JPE 11-4-13

\title{
A Three-Phase High Frequency Semi-Controlled Battery Charging Power Converter for Plug-In Hybrid Electric Vehicles
}

\author{
Mahmoud M. Amin* and Osama A. Mohammed ${ }^{\dagger}$ \\ $\dagger *$ Dept. of Electrical and Computer Eng., Florida International University, Florida, United States
}

\begin{abstract}
This paper presents a novel analysis, design, and implementation of a battery charging three-phase high frequency semicontrolled power converter feasible for plug-in hybrid electric vehicles. The main advantages of the proposed topology include high efficiency; due to lower power losses and reduced number of switching elements, high output power density realization, and reduced passive component ratings proportionally to the frequency. Additional advantages also include grid economic utilization by insuring unity power factor operation under different possible conditions and robustness since short-circuit through a leg is not possible. A high but acceptable total harmonic distortion of the generator currents is introduced in the proposed topology which can be viewed as a minor disadvantage when compared to traditional boost rectifiers. A hysteresis control algorithm is proposed to achieve lower current harmonic distortion for the rectifier operation. The rectifier topology concept, the principle of operation, and control scheme are presented. Additionally, a dc-dc converter is also employed in the rectifier-battery connection. Test results on $50-\mathrm{kHz}$ power converter system are presented and discussed to confirm the effectiveness of the proposed topology for PHEV applications.
\end{abstract}

Key Words: Battery control strategy, Plug-in hybrid electric vehicles, Power factor control, Three-phase PWM rectifiers

\section{INTRODUCTION}

Plug-in hybrid electric vehicles (PHEVs) are gaining popularity because of the environmental consideration "Go green" factor. PHEV is a hybrid electric vehicle (HEV) with a very high capacity battery pack that can be recharged by plug-in to the power in a local grid, where the power generation source can be in the form of renewable energy such as wind, solar, etc [1]. The Electric Power Research Institute (EPRI) projects that by $2050,62 \%$ of the entire US vehicle fleet would consist of PHEVs [2]. Other than having the environmental benefits and lessening the nation's dependence on oil, PHEVs also have the potential for providing peak power shaving via V2G (Vehicle to Grid) and powering home in emergency situations via $\mathrm{V} 2 \mathrm{H}$ (Vehicle to Home).

Although most of the HEVs currently available on the market are equipped with Ni-MH batteries, the lead-acid batteries are still attractive and used in the mild HEVs, which have relatively restricted functions and require consideration of cost effectiveness. Lead-acid batteries represent both reasonable cost and high reliability in automotive applications, but they generally show some drawbacks in cycle life, power character-

Manuscript received Jan. 12, 2011; revised May 29, 2011

Recommended for publication by Guest Associate Editor Byoung-Kuk Lee.

$\dagger$ Corresponding Author: mohammed@ @iu.edu

Tel: +1-305-348-3040, Fax: +1-305-348-3707, FIU

* Dept. of Electrical and Computer Eng., Florida, International University, United States

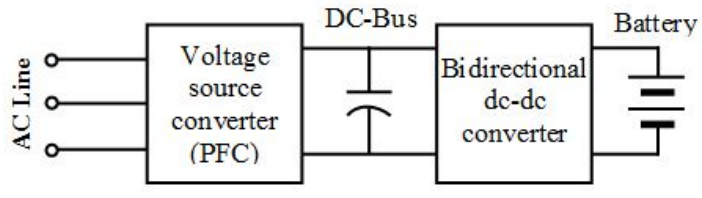

Fig. 1. Block diagram of battery charger for PHEV.

istics, and weight, etc. Studies to improve their performance are being continuously performed, and different viewpoints have arisen providing resolutions other than strictly improving the battery itself [3]-[6]. Moreover, further improvement could be achieved when a proper storage device is selectively used corresponding to respective charging status and vehicle driving conditions, which can be called an advanced Hybrid Energy Storage System (advancedHESS) [7].

High frequency (HF) operation of power converters have become a mature technology with several international manufacturers of power electronic devices [8]-[13]. Recent power converters tend to increase switching frequency to reduce the size and volume of the passive components; inductors and capacitors. However, HF operation increases semiconductor device switching loss, which is proportional to the switching frequency [14]. The latest power semiconductor devices have a fast turn-on and turn-off capability to reduce the switching loss at HF operation [15]-[17].

A PHEV requires an ac outlet charging system for charging the battery. Usually ac-dc converters are used in a number 
of applications such as power supply, household electric appliances, battery charger, etc. Depending on the switching frequency they are classified as converters with low switching frequency and those with high switching frequency [18], [19].

Conventional uncontrolled rectifiers and line commutated phase controlled rectifiers so far have dominated the ac-dc power conversion. Such converters have inherent drawbacks such as harmonics in the input current and output voltage; low input power factor especially at low output voltage since these conventional rectifiers draw non-sinusoidal currents from the grid [20]. Since power devices demand reactive power in addition to active power, a charger with low power factor increases burden on the connecting power system.

On the other hand, harmonics have a negative effect in the operation of the electrical system. Therefore, an increasing attention is paid to their mitigation and control. The problems due to harmonics in conventional rectifiers have resulted in the establishment of standards such as IEC 61000-3-2 and IEEE Std $519^{\mathrm{TM}}-1992$ [21], [22]. Thus, a PHEV charger with a Power Factor Correction (PFC) based ac-dc converter is desirable.

Voltage source converter or synchronous link converter is the best solution under such situation, which has both rectification and regeneration capability. The input current in these converters flows through the inductor which can be wave shaped with appropriate current mode control. These converters have high efficiency and inherent power quality improvement at the ac input and dc output [23].

In this paper, a new battery charging topology feasible for PHEV applications is proposed. This topology consists of a three-phase high frequency semi-controlled rectifier and dc-dc converter. The block diagram of this battery charger is shown in Fig. 1. Robustness, simplicity, low cost, and high efficiency are inherent characteristics because high frequency and few semiconductor elements are used. The operating principle, theoretical analysis, as well as experimental results obtained from a $50-\mathrm{kHz}$ prototype are presented and discussed.

This paper is organized as follows: The proposed conversion topology dynamic modeling is explained in Section II. In Section III, PI controller design for maintaining the dc link voltage and hysteresis controller design for the current control is described. In Section IV, the hardware implementation and experimental results for the proposed PHEV charging system are illustrated. Some conclusions are given in Section V.

\section{The Proposed CONVERSION TOPOLOGY}

The semi-controlled rectifier structure, which is proposed here, uses three insulated-gate bipolar transistors (S1-S3 IGBTs) and three diodes (D1-D3), is shown in Fig. 2 [8]. The main advantages of the proposed topology over the traditional fully-controlled topology are:

1) All switches are connected to the same reference in rectifier stage; simplifying the command circuit.

2) Protection; as short-circuit through a leg is not possible.

3) Higher efficiency; due to less number of switches.

4) Smaller size; since passive elements are reduced proportionally due to high frequency operation.

5) Unity power factor (UPF) operation can be achieved.

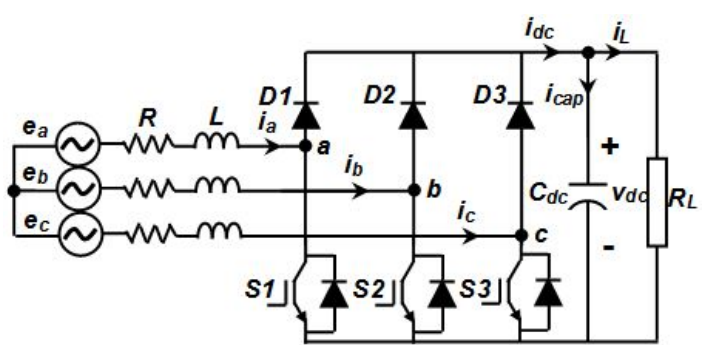

(a)

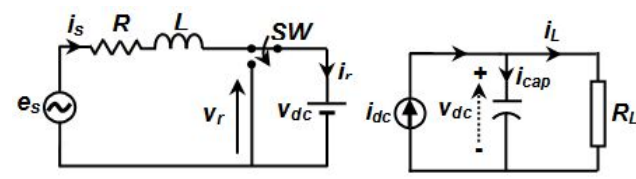

(b)

(c)

Fig. 2. Ac-dc PWM semi-controlled rectifier. (a) Power circuit, (b) per-phase input equivalent circuit, (c) output equivalent circuit.

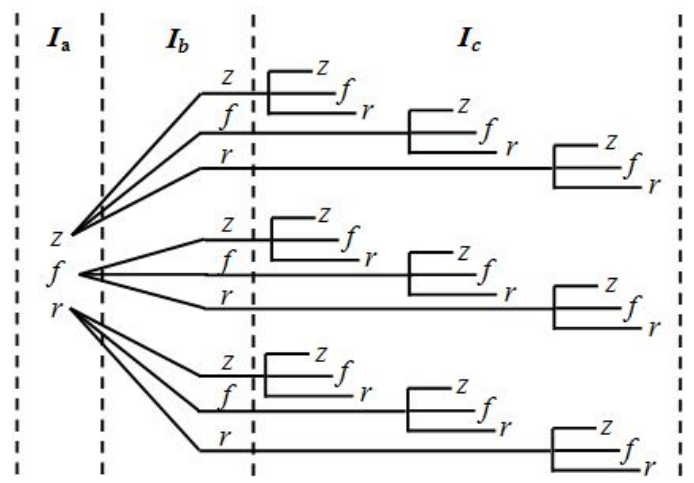

Fig. 3. All possible combinations for converter current flow.

\section{A. Power Transfer Operation}

The proposed rectifier in Fig. 2 operates as a boost rectifier. When any switch $\mathrm{S} 1, \mathrm{~S} 2$, or $\mathrm{S} 3$ is turned on then the current will flow through it and respective input inductor current will increase, while respective diode D1, D2, or D3 is reverse biased (off). On the other hand, when S1, S2, or S3 is turned off then the current will flow through the respective diode D1, D2, or D3 (forward biased) and energy will be transferred to dc-bus.

According to current direction, three states are representing each phase current $I_{a}, I_{b}$, and $I_{c}$. These states can be simplified as: zero $(z)$, forward $(f)$, and reverse current flow $(r)$, resulting in 27 different states as shown in Fig. 3. Only 12 states are physically implemented as shown in Table I. There are three states $(10,11$, and 12) will not be implemented for rectification mode of operation; since no power will be transferred to dcbus. The other nine states can be subdivided into three groups; (1, 4, and 7), (2, 5, and 8), and (3, 6, and 9). Therefore, states 1-3 will be repeated with 4-6 as well as 7-9.

Fig. 4 shows the current waveforms for all rectification

TABLE I

THE PHYSICAL VALID CURRENT FLOW FOR RECTIFIER OPERATION

\begin{tabular}{ccccccccccccc}
\hline & 1 & 2 & 3 & 4 & 5 & 6 & 7 & 8 & 9 & 10 & 11 & 12 \\
\hline$I_{a}$ & $f$ & $F$ & $f$ & $f$ & $z$ & $r$ & $r$ & $r$ & $z$ & $f$ & $r$ & $r$ \\
$I_{b}$ & $f$ & $Z$ & $r$ & $r$ & $r$ & $z$ & $f$ & $f$ & $f$ & $r$ & $f$ & $r$ \\
$I_{c}$ & $r$ & $R$ & $z$ & $f$ & $f$ & $f$ & $f$ & $z$ & $r$ & $r$ & $r$ & $f$ \\
\hline
\end{tabular}




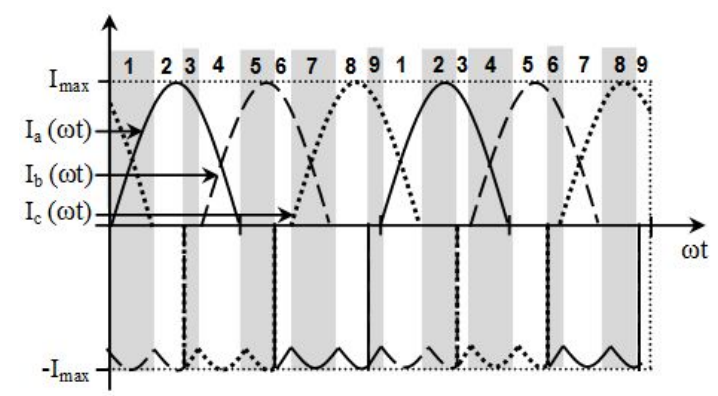

Fig. 4. Theoretical current waveforms for the nine rectification physical states.

possible states 1-9 where only the positive half cycle is modulated while negative half cycle is uncontrolled.

\section{B. Rectifier Dynamic Model}

The semi-controlled rectifier structure, which is proposed here, uses three insulated-gate bipolar transistors (S1-S3 IGBTs) and three diodes (D1-D3). A power circuit, per-phase and output equivalent circuits of a three-phase semi-controlled rectifier are shown in Fig. 2. It is assumed that a resistive load $R_{L}$ is connected to the output terminal. An input voltage equation is derived from Fig. 2(b):

$$
e_{s}=R i_{s}+L \frac{d i_{s}}{d t}+v_{r}
$$

where $e_{s}$ is the source voltage, $i_{s}$ is the ac-current, $v_{r}$ is the rectifier input voltage, and $R, L$ are the resistance and inductance of the boosting inductor, respectively. The instantaneous average voltages $\left(V_{s 1}, V_{s 2}\right.$, and $\left.V_{s 3}\right)$ seen by each phase are given by:

$$
\left[\begin{array}{l}
V_{s 1}(t) \\
V_{s 2}(t) \\
V_{s 3}(t)
\end{array}\right]=\left[\begin{array}{l}
\left(1-D_{s 1}(t)\right) \\
\left(1-D_{s 2}(t)\right) \\
\left(1-D_{s 3}(t)\right)
\end{array}\right] V_{d c}
$$

where $D_{s 1}(t), D_{s 2}(t)$, and $D_{s 3}(t)$ are instantaneous functions of the effective duty cycle of switches $S 1, S 2$, and $S 3$, respectively. Considering the ac-source voltages balanced and the presence of the neutral conductor, and applying the Kirchhoff's law and Laplace transform, the dynamic model of the rectifier is obtained and given in matrix form by:

$$
\left[\begin{array}{l}
I_{a}(s) \\
I_{b}(s) \\
I_{c}(s)
\end{array}\right]=\frac{1}{3 L_{s}}\left[\begin{array}{ccc}
-2 & 1 & 1 \\
1 & -2 & 1 \\
1 & 1 & -2
\end{array}\right]\left[\begin{array}{l}
V_{s 1}(s) \\
V_{s 2}(s) \\
V_{s 3}(s)
\end{array}\right] .
$$

For fast voltage control, the input power should supply instantaneously the sum of load power and charging rate of the capacitor energy. On the dc-output side in Fig. 2(c):

$$
i_{d c}=C_{d c} \frac{d v_{d c}}{d t}+i_{L}
$$

where $v_{d c}, i_{d c}, C_{d c}$ are the dc-link output voltage, current, and filter capacitor, respectively. $i_{L}$ is the load current.

\section{Bidirectional DC-DC Converter}

Bidirectional (regenerative) power flow can be obtained with a current-bidirectional two quadrant realization of the switch network. An example is illustrated in Fig. 5, in which a dc-dc converter interfaces batteries to the main dc power bus of a

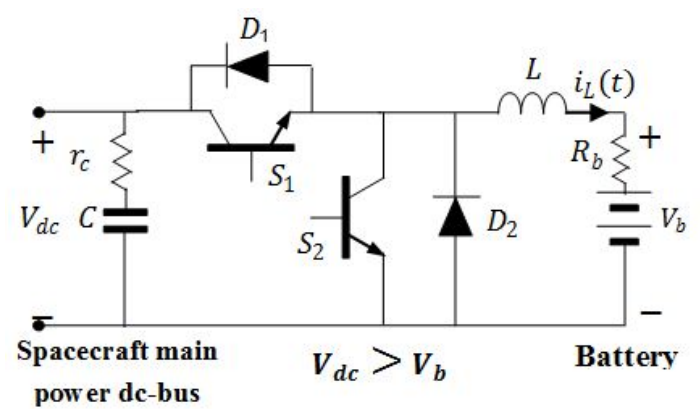

Fig. 5. A buck converter with two-quadrant switches and bidirectional power flow. Battery charger / discharger example.

spacecraft. The anti-parallel-connected transistors and diodes form current-bidirectional switches. Switch S2 is driven with the complement of the $\mathrm{S} 1$ drive signal, such that $\mathrm{S} 2$ is off when $\mathrm{S} 1$ is on, and vice-versa. To charge the battery, the inductor current $i_{L}(t)$ is positive and flows through transistor $\mathrm{S} 1$ and diode D2. To discharge the battery, the current $i_{L}(t)$ reverses polarity, and flows through transistor S2 and diode D1. In both cases, the battery voltage is less than the main dc bus voltage. The magnitude and polarity of the battery current can be controlled via adjustment of the duty cycle $D$.

To design the control system of a converter, it is necessary to model the converter dynamic behavior.

In particular, it is of interest to determine how variations in the power input voltage $V_{d c}$, the load current $i_{L}$, and the duty cycle $D$ affect the output voltage. Unfortunately, understanding of converter dynamic behavior is hampered by the nonlinear time-varying nature of the switching and pulse-width modulation (PWM) process. These difficulties can be overcome through the use of waveform averaging and small signal modeling techniques [24]. A well-known converter modeling technique known as state-space averaging is briefly described here. The model equations are derived below. When state switch $\mathrm{S} 1$ is on and S2 is switched off, based on Kirchhoff's laws:

$$
\left[\begin{array}{c}
p V_{c} \\
p I_{L}
\end{array}\right]=\left[\begin{array}{cc}
-1 / C r_{c} & 0 \\
0 & -R_{b} / L
\end{array}\right]\left[\begin{array}{c}
V_{c} \\
I_{L}
\end{array}\right]+\left[\begin{array}{cc}
1 / C r_{c} & 0 \\
1 / L r_{c} & 1 / L
\end{array}\right]\left[\begin{array}{c}
V_{d c} \\
V_{b}
\end{array}\right]
$$

The state space equation in the matrix form for the converter during off state is given by:

$$
\left[\begin{array}{l}
p V_{c} \\
p I_{L}
\end{array}\right]=\left[\begin{array}{cc}
-1 / C r_{c} & 0 \\
0 & -R_{b} / L
\end{array}\right]\left[\begin{array}{l}
V_{c} \\
I_{L}
\end{array}\right]+\left[\begin{array}{cc}
1 / C r_{c} & 0 \\
0 & 1 / L
\end{array}\right]\left[\begin{array}{c}
V_{d c} \\
V_{b}
\end{array}\right]
$$

where $p$ is the derivative operator; i.e. $p=d / d t$. Combining the two subsystems the averaged state space equation can be written as:

$$
\begin{aligned}
\dot{X} & =A x+b V_{d c}+e V_{b} \\
A & =A_{1} d+A_{2}(1-d) \\
B & =b_{1} d+b_{2}(1-d) \\
E & =e_{1} d+e_{2}(1-d) .
\end{aligned}
$$

The state space equation for the output can be written as:

$$
\begin{aligned}
& Y=C x+D u \\
& C=C_{1} d+C_{2}(1-d) \\
& D=D_{1} d+D_{2}(1-d)
\end{aligned}
$$


where $d$ is the duty cycle and the matrices are given by:

$$
\begin{aligned}
& A_{1}=\left[\begin{array}{cc}
-d / C r_{c} & 0 \\
0 & -d R_{b} / L
\end{array}\right] \\
& A_{2}=\left[\begin{array}{cc}
-(1-d) / C r_{c} & 0 \\
0 & -(1-d) R_{b} / L
\end{array}\right] \\
& b_{1}=\left[\begin{array}{l}
b / C r_{c} \\
d / L r_{c}
\end{array}\right], \quad b_{2}=\left[\begin{array}{c}
(1-d) / C r_{c} \\
0
\end{array}\right] \\
& e_{1}=\left[\begin{array}{c}
0 \\
d / L
\end{array}\right], \quad e_{2}=\left[\begin{array}{c}
0 \\
(1-d) / L
\end{array}\right] \\
& C_{1}=\left[\begin{array}{ll}
0 & 1 \\
1 & 0
\end{array}\right] \quad C_{2}=\left[\begin{array}{ll}
0 & 1 \\
1 & 0
\end{array}\right] \\
& D_{1}=\left[\begin{array}{ll}
0 & 0
\end{array}\right]^{T} \quad D_{2}=\left[\begin{array}{ll}
0 & 0
\end{array}\right]^{T}
\end{aligned}
$$

The input to output transfer function can be written as:

$$
\frac{\tilde{y}(s)}{\tilde{u}(s)}=C_{a v}\left[S I-A_{a v}\right]^{-1} B_{a v}+D_{a v}
$$

where $\tilde{y}(s)$ is the output and $\tilde{u}(s)$ is the input in Laplace form. Also the averaged matrices are given by:

$$
\begin{aligned}
C_{a v} & =\left[\begin{array}{ll}
0 & 1 \\
1 & 0
\end{array}\right] \quad A_{a v}=\left[\begin{array}{cc}
-1 / C r_{c} & 0 \\
0 & -R_{b} / L
\end{array}\right] \\
B_{a v} & =\left[\begin{array}{cc}
1 / C r_{c} & 0 \\
d / L r_{c} & 1 / L
\end{array}\right] \quad D_{a v}=\left[\begin{array}{l}
0 \\
0
\end{array}\right]
\end{aligned}
$$

\section{The CONTROL SySteM}

Fig. 6 shows the schematic diagram for the overall proposed PHEV charging system. The diagram is involving the control strategy for each conversion stage as follows:

\section{A. Rectifier Control}

Using PI-voltage controller, the dc- voltage can be regulated by choosing the dc-current reference, $i_{\text {ref }}(t)$ such that,

$$
i_{r e f}(t)=K_{p}^{v} \cdot\left[V_{d c}^{r}-V_{d c}(t)\right]+K_{i}^{v} \cdot \int\left[V_{d c}^{r}-V_{d c}(t)\right] d t
$$

where $V_{d c}^{r}$ is the desired dc-voltage, $K_{p}^{v}, K_{i}^{v}$ are the constant gains of the PI-voltage controller. Fig. 7 shows the dc-bus voltage controller operation. Through simulation studies, it was verified that constant frequency PWM controllers tend to increase the current THD due to the duty cycle discontinuities.

Then, the rectifier control system uses the principle of hysteresis control as shown in Fig. 8. The input currents through each phase $\left(I_{a b c}\right)$ are measured and compared to the respective reference currents $\left(I_{a b c}^{r}\right)$. The reference current shapes are obtained from the respective input voltages, and their peak values are given the voltage controller. A second order software phase-locked loop (SPLL) is proposed here to precisely detect the ac-source phase angle and multiply it by the current peak values in order to obtain the reference current signal for the hysteresis current controller. Switching operation occurs when the current limits are reached, as shown in Fig. 9. With this technique, the obtained line currents achieve low THD with a simple control circuitry. The main disadvantage of the hysteresis control is the variable switching frequency. However, switching frequency can be maintained within acceptable range by adjusting the hysteresis band (HB).
The HB method switches the IGBTs (S1-S3) when the error between $I_{a b c}^{r}$ and $I_{a b c}$ exceeds a fixed magnitude: the hysteresis band. As can be seen in Fig. 8, this type of control needs a single comparator with hysteresis per phase. In this case the switching frequency is not determined, but its maximum value can be evaluated such that [25]:

$$
F_{s}^{\max }=\frac{V_{d c}}{4 h \cdot L_{1}}
$$

where $F_{s}^{\max }$ is the maximum switching frequency, $L_{1}$ is the line input inductor, and $h$ is the $\mathrm{HB}$ magnitude.

\section{B. Battery Control}

The primary goal of the battery converter is to regulate the common dc-bus voltage which must be regulated to stay within a stable region regardless of the battery-current variation. To do this, a modified hysteresis-control strategy is applied. The concept of this strategy is to regulate the common dc voltage within a specific band, for example, a hysteresis band. Therefore, the battery charger/discharger is controlled in such a way that the dc-bus voltage should not violate the specified upper and lower limits, $V_{d c_{-} u p}$ and $V_{d c_{-} l o w}$, as shown in Fig. 9.

A decision criterion for charging/discharging becomes the level of the common dc-bus voltage and the battery buckbooster operates according to the scheme as below:

$$
\begin{aligned}
& \text { If } V_{d c}>V_{d c_{-} u p} \text {, then charging: } V_{d c}^{r}=V_{d c_{-} u p} \\
& \text { If } V_{d c}<V_{d c_{-} l o w} \text {, then charging: } V_{d c}^{r}=V_{d c_{-} l o w} \\
& \text { If } V_{d c_{-} l o w} \leq V_{d c} \leq V_{d c_{-} u p} \text {, then no control (rest). }
\end{aligned}
$$

When the common dc voltage $V_{d c}$ becomes larger than the upper limit, charging mode begins with the voltage command $V_{d c}^{r}$ equal to the upper limit and continues until the dc voltage reaches the limit. If $V_{d c}$ goes below the lower limit, then the voltage target is bound at the lower limit and the converter starts operating in boost mode. Accordingly, the battery-mode control block in Fig. 6 can be built as shown in Fig. 11.

There is another reason for such hysteresis control other than voltage regulation of the dc bus. It is intended to protect the battery storage against excessive charging frequency and current variation. Not by bounding dc-bus voltage at a constant value but by allowing a hysteresis band; the battery can take a rest during the rest interval in Fig. 10. Energy that can be extracted or stored across the hysteresis band in a dc-bus capacitor $\Delta E_{c}$ is described as follows:

$$
\Delta E_{c}=\frac{1}{2} C_{d c}\left(V_{d c_{-} u p}^{2}-V_{d c_{-} l o w}^{2}\right) .
$$

\section{Efficiency Estimation}

A main part of total losses is the switching and conduction losses which depend on switching times and switching frequency. Fig. 12 shows the waveforms for switching times. The switching loss can be reduced by decreasing the switching time, but fast switching increases $d v / d t$ and $d i / d t$ which affects electromagnetic interference (EMI) noise. 


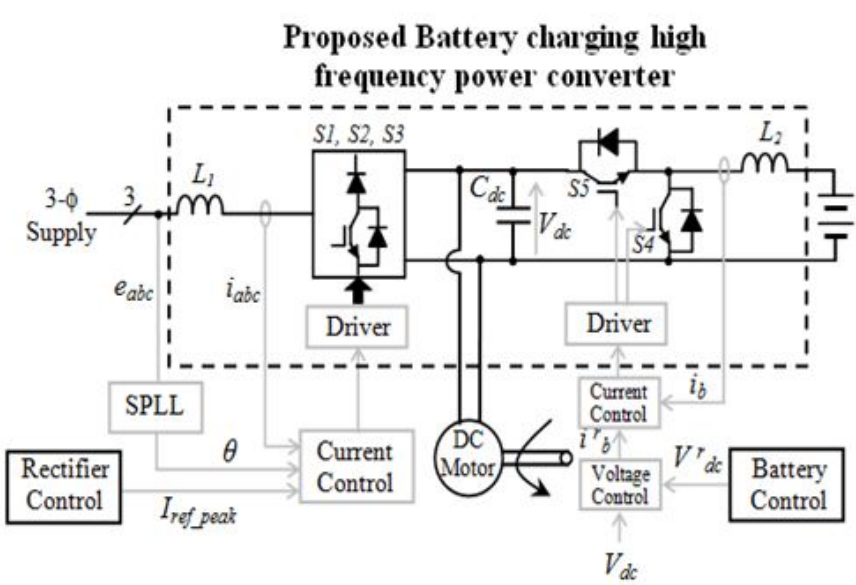

(a)

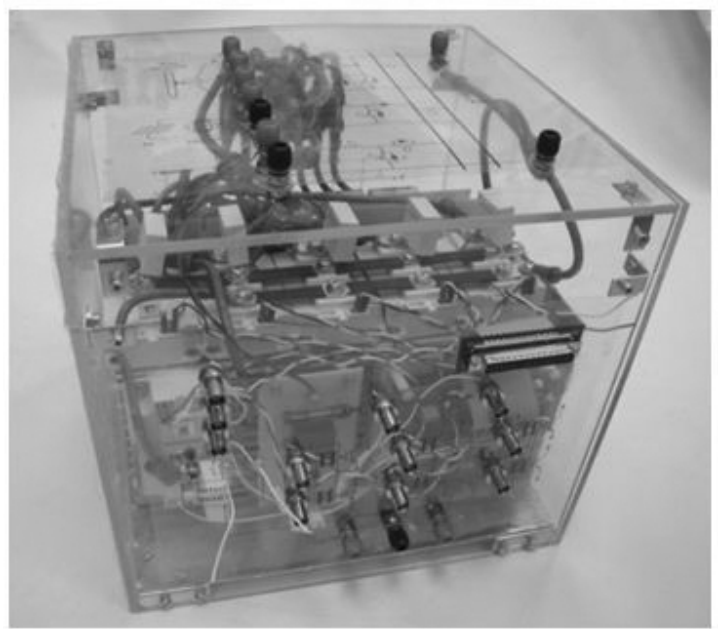

(b)

Fig. 6. The proposed battery charging converter and its control strategy. (a) Schematic diagram, (b) hardware converter module.

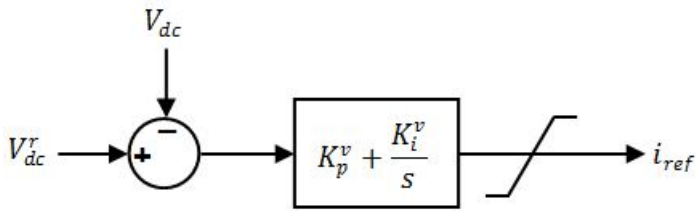

Fig. 7. Voltage controller for rectifier operation.

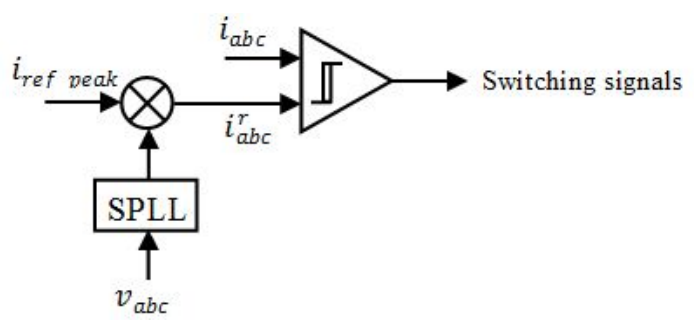

Fig. 8. Hysteresis current controller for rectifier operation.

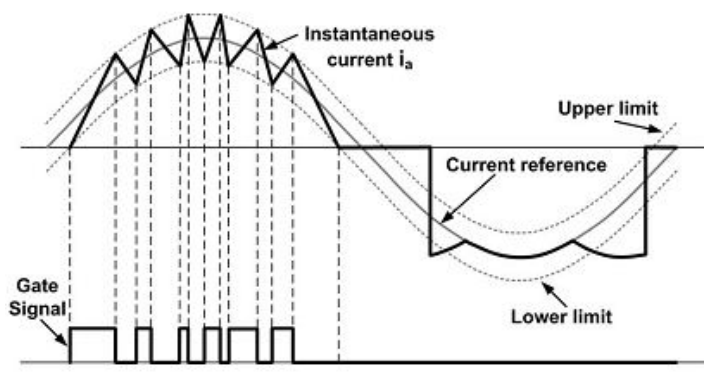

Fig. 9. Switching pattern of the hysteresis control applied to the rectifier stage.

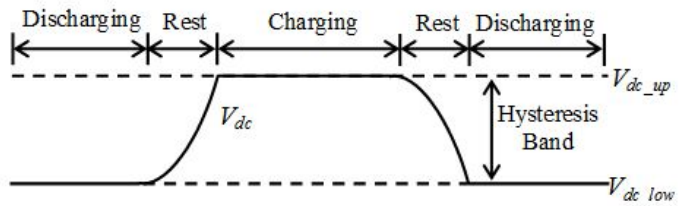

Fig. 10. Modified hysteresis battery control strategy.

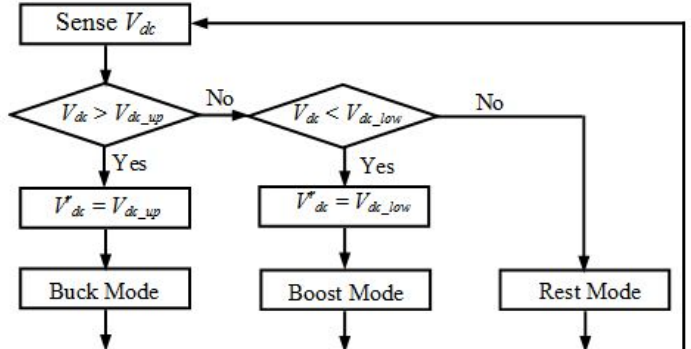

Fig. 11. Battery-mode control block (modified hysteresis).

The average power loss in a switch over one switching cycle is given by the following equation which consists of the conduction and switching losses:

$$
\bar{P}_{s}=\frac{1}{T_{s w}} \int_{0}^{T_{s w}} i_{s w} v_{s w} d t=\bar{P}_{c o n d}+\bar{P}_{s w} .
$$

Assuming that the on and off switching times are small compared to switching cycle, $T_{s w}$, and the leakage current is negligible, $I_{\text {off }}=0$. Thus the conduction loss is given by:

$$
\bar{P}_{\text {cond }}=V_{\text {on }} I_{o n} D, \quad D=\frac{t_{\text {on }}}{T_{s w}}
$$

where $t_{o n}$ is the time when the switch is in on-state, $V_{o n}$ is a voltage drop across the switch, $I_{\text {on }}$ is a current through the switch assuming it is constant in magnitude and $D$ is a duty cycle. The switching loss should be calculated based on instantaneous current and voltage waveforms as follows:

$$
\bar{P}_{s w}=f_{s w}\left(\int_{0}^{t_{s w o n}} v_{s w} i_{s w} d t+\int_{0}^{t_{s w}} v_{s w} i_{s w} d t\right)
$$

where $t_{s w_{-} o n}$ and $t_{s w_{-} \text {off }}$ are turn- on and turn-off switching times.

Also, the total average power losses can be calculated as follows:

$$
P_{a v \_l o s s}=f_{s w}\left[\frac{1}{2} V_{d} I_{o n} t_{s w_{o n}}+\frac{1}{2} V_{d} I_{o n} t_{s w_{o f f}}+V_{o n} I_{o n} D\right] .
$$




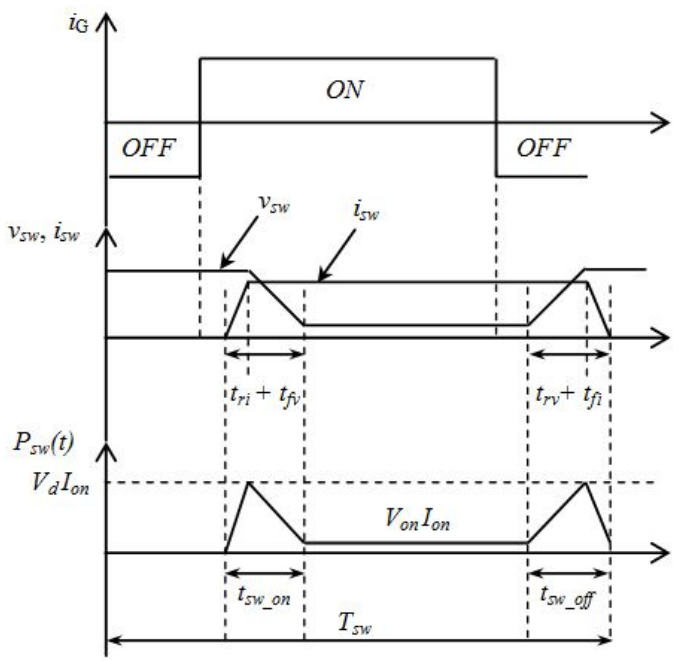

Fig. 12. The voltage, current, and power waveforms for power switches.

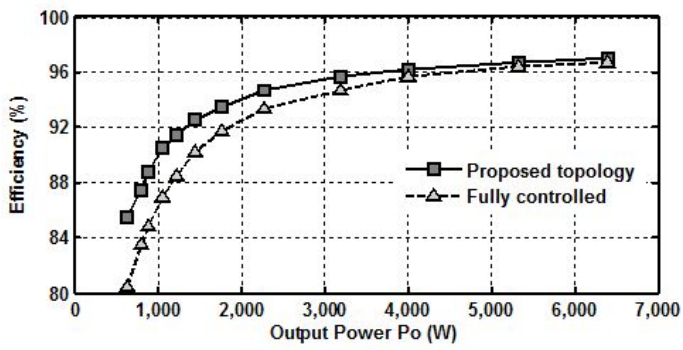

Fig. 13. Estimated efficiencies for the proposed topology $\left(\eta_{1}\right)$ and the fullycontrolled topology $\left(\eta_{2}\right)$.

In a power electronic system, there are other circuits such as gate drives, controllers, sensors and passive filters which consume power. The total losses are the sum of all losses and the efficiency of a system $(\eta)$ can be calculated based on input power $\left(P_{i n}\right)$ and total losses $\left(P_{\text {loss }}\right)$ as given below:

$$
\eta=\frac{\bar{P}_{\text {out }}}{\bar{P}_{\text {in }}}=\frac{\bar{P}_{\text {in }}-\bar{P}_{\text {loss }}}{\bar{P}_{\text {in }}}=1-\frac{\bar{P}_{\text {loss }}}{\bar{P}_{\text {in }}} .
$$

In order to estimate the efficiency of the proposed rectifier, a loss analysis was performed, considering the developed equations, the semiconductors, and parameters given in Table II and the respective datasheets. Fig. 13 compares the estimated efficiency of the proposed rectifier stage $\left(\eta_{1}\right)$ with the fullycontrolled rectifier topology $\left(\eta_{2}\right)$. In the fully controlled bridge structure, the currents can be modulated in both half cycles which leads to less input current harmonic distortion when compared to the proposed half controlled bridge topology. However, it has more complicated operation and control process; since it has larger switching losses and it requires the use of bootstrap-integrated circuits. Moreover, the occurrence of eventual short-circuits through the leg is possible. It can be seen that the proposed rectifier has improved efficiency over the entire power range, due to the fewer number of semiconductors, which is an interesting advantage in PHEV applications.

\section{EXPERIMENTAL RESULtS}

A $60-\mathrm{kW}$ prototype of the proposed battery charging high frequency power converter was developed. Fig. 6 shows
TABLE II

SEMICONDUCTOR DEVICES AND ITS PARAMETERS

\begin{tabular}{cc|cc}
\hline \multicolumn{2}{c|}{ Proposed topology } & \multicolumn{2}{c}{ Fully-controlled topology } \\
\hline Parameter & Specification & Parameter & Specification \\
\hline$S_{1}-S_{3}, D_{1}-D_{3}$ & SKM & $S_{1}-S_{6}$ & SKM \\
& $50 \mathrm{GAL125 \textrm {D }}$ & & $50 \mathrm{~GB} 125 \mathrm{D}$ \\
\hline$V_{\text {Switch }}$ & $1200 \mathrm{~V}$ & $V_{\text {Switch }}$ & $1200 \mathrm{~V}$ \\
\hline$I_{\text {Switch }}$ & $50 \mathrm{~A}$ & $I_{\text {Switch }}$ & $50 \mathrm{~A}$ \\
\hline Power rating & $60 \mathrm{~kW}$ & Power rating & $60 \mathrm{~kW}$ \\
\hline \multicolumn{2}{c}{}
\end{tabular}

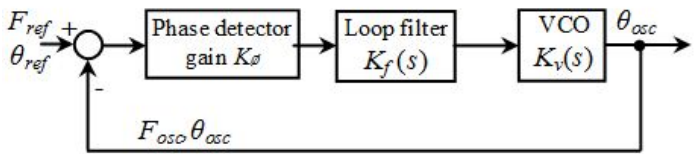

Fig. 14. Basic PLL block diagram.

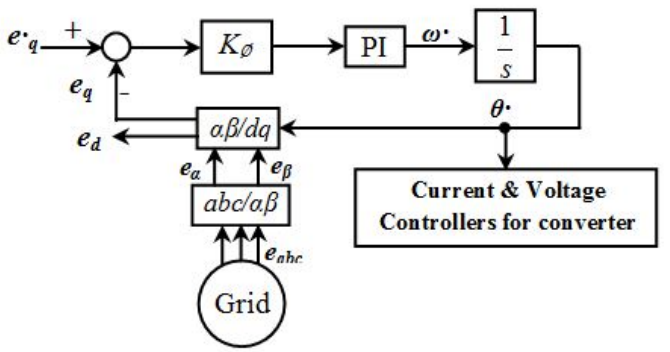

Fig. 15. SPLL applied for ac-grid voltage.

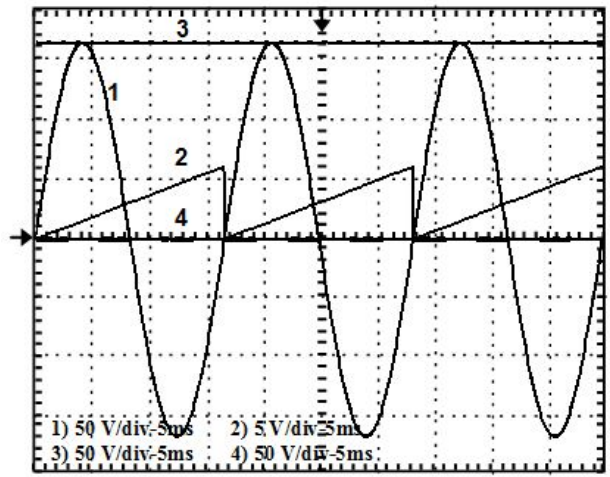

Fig. 16. Grid voltage (1-50 V/div, $5 \mathrm{~ms})$, phase angle (2-5V/div, $5 \mathrm{~ms})$, and synchronous frame $d q$ voltage waveforms (3, 4-50 V/div, 5ms) for phase "a".

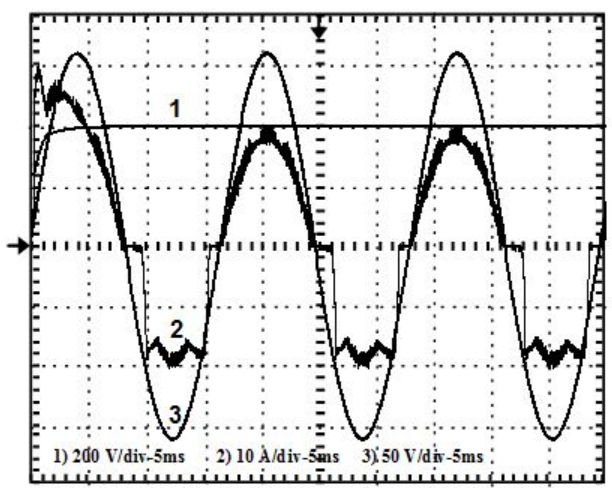

Fig. 17. DC-bus output voltage (1-200 V/div, 5ms), rectifier current (2-10 A/div, 5ms), and grid voltage (3-50 V/div, $5 \mathrm{~ms})$ for phase "a". 
TABLE III

RECTIFIER SPECIFICATIONS AND PARAMETERS

\begin{tabular}{cc}
\hline Parameter & Specification \\
\hline Input voltage range & $70-208 \mathrm{Vrms}$ \\
Line input inductor $\left(L_{1}\right)$ & $0.3 \mathrm{mH}$ \\
Inductor internal resistance & $0.012 \Omega$ \\
DC-bus capacitor $\left(C_{d c}\right)$ & $1000 \mu \mathrm{f}$ \\
DC-bus voltage $\left(V_{d c}\right)$ & $400 \mathrm{~V}$ \\
Switching frequency $\left(f_{s w}\right)$ & $30-45 \mathrm{kHz}$ \\
\hline
\end{tabular}

TABLE IV

BATTERY AND DC-DC CONVERTER SPECIFICATIONS \& PARAMETERS

\begin{tabular}{cc|cc}
\hline \multicolumn{2}{c|}{ DC-DC Converter } & \multicolumn{2}{c}{ Battery Bank } \\
\hline Parameter & Specification & Parameter & Specification \\
\hline$V_{d c}$ & $400 \mathrm{~V}$ & rated voltage & $160 \mathrm{~V}$ \\
$L_{2}$ & $0.15 \mathrm{mH}$ & Connection & 10 -series \\
Switch & IGBT & rated capacity & $100 \mathrm{AH}$ \\
$f_{s w}$ & $50 \mathrm{kHz}$ & Battery type & Lead-acid \\
Control & Bulk/absorption/float & Total power & $12 \mathrm{~kW}$ \\
\hline
\end{tabular}

the prototype schematic diagram and a photograph for its hardware implementation. The high frequency power converter module has been designed and implemented in the energy systems research laboratory (ESRL). It is composed of a semi-controlled rectifier and a bidirectional dc-dc converter. The individual converters are controlled by their own TMS320F28335-based control platforms. The specifications and parameters used in the prototype are shown in Tables III and IV.

\section{A. Second Order SPLL for Phase Angle Detection}

A good detection of the phase angle of the ac power is highly recommended in PHEV systems utilizing converterinverter unites. A fully software PLL for the phase angle detection of the three phase voltage is proposed here using the $d q$ synchronous reference frame. Fig. 14 shows a basic block diagram of the applied PLL. The output of the voltage controlled oscillator (VCO), $F_{r e f}$, is fed-back to the phase frequency detector input, and comparison continue until both frequency and phase are made the same and the phase and frequency of the $\mathrm{VCO}$ are in locked state with reference signal i.e. $F_{o s c}=F_{r e f}, \theta_{o s c}=\theta_{\text {ref }}$. The closed loop transfer function of the PLL system of Fig. 14 can be expressed as:

$$
W(s)=\frac{\theta_{\text {osc }}(s)}{\theta_{\text {ref }}(s)}=\frac{K_{\phi} K_{f}(s) K_{v}(s)}{1+K_{\phi} K_{f}(s) K_{v}(s)} .
$$

The VCO transfer gain $K_{v}(s)$ is a function of time, since phase is the time integral of frequency, it may be written as:

$$
K_{v}(s)=\frac{K_{v}}{s} .
$$

The phase frequency detector gain, $K_{\phi}$, is assumed to be independent of frequency. With unity VCO gain, $K_{v}=1$, (19) can be rewritten as:

$$
W(s)=\frac{K_{\phi} K_{f}(s)}{S+K_{\phi} K_{f}(s)} .
$$

There are several methods to design the loop filter. The $2^{\text {nd }}$ order loop filter is commonly used as a good trade-off of the filter performance and system stability [26]. The $2^{\text {nd }}$ order PI-loop filter can be expressed in the form:

$$
K_{f}(s)=K_{p}+K_{i} / s
$$

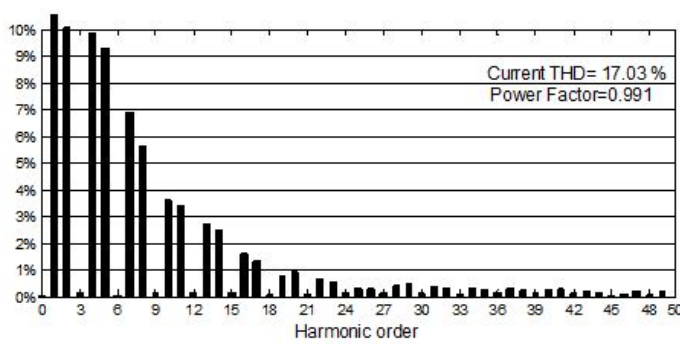

(a)

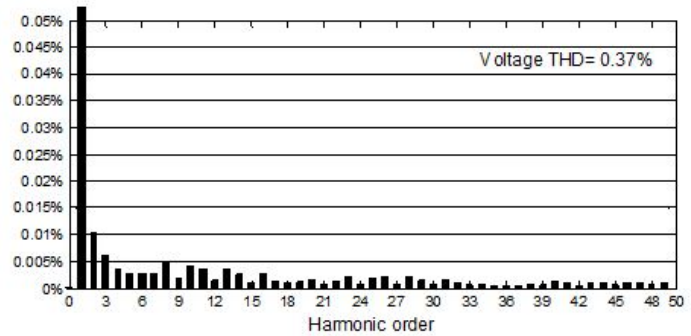

(b)

Fig. 18. Harmonic spectrum of (a) The generator voltage, (b) the input current.

where $K_{p}$ and $K_{i}$ denote the gain parameters of the PI loop filter, therefore:

$$
W(s)=\frac{K_{\phi} K_{p} s+K_{\phi} K_{i}}{s^{2}+K_{\phi} K_{p} s+K_{\phi} K_{i}} .
$$

The general form of the closed loop transfer function of the second order system is given by:

$$
W(s)_{\text {General }}=\frac{\omega_{n}^{2}}{s^{2}+2 \xi \omega_{n} s+\omega_{n}^{2}} .
$$

A second-order loop filter design was proposed here as a good trade-off of the filter performance and system stability. The main objective of this design is to precisely detecting the phase angle during presence of the 5th and 7th harmonics. Comparing (23) with (24):

$$
K_{i}=\frac{\omega_{n}^{2}}{K_{\phi}} \quad \text { and } \quad K_{p}=\frac{2 \xi \omega_{n}}{K_{\phi}} .
$$

The PI-filter gain parameters were designed and analyzed to meet the time domain specification: minimum overshot, minimum settling time and minimum steady-state error such that the natural frequency $\left(\omega_{n}\right)=314 \mathrm{rad} / \mathrm{sec}$ and the damping ratio $(\xi)=0.707$.

Accordingly, the gain parameters have been calculated from (25) such that $K_{p}=2.62$ and $K_{i}=580.98$. The configuration of the PLL system using the $d q$ components in the synchronous reference frame of the three phase input voltage is shown in Fig. 15. Figure 16 shows the response of the SPLL system at $60 \mathrm{~Hz}, 110 \mathrm{~V}$. The synchronous reference frame $d q$ voltage appears as dc-values.

\section{B. Rectifier Performance}

Fig. 17 shows the dc-bus voltage, the current through phase "a," and the respective grid phase voltage. The dc-bus voltage has no overshoot and low voltage ripple of $2.3 \%$. Fig. 18 shows the harmonic spectrum of the grid voltage 


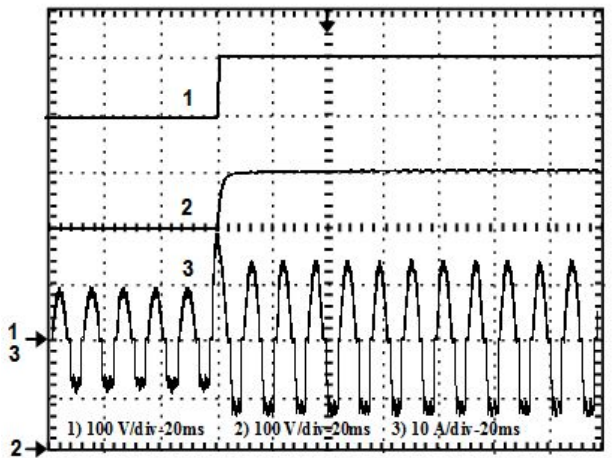

Fig. 19. The reference and actual dc-bus voltage (1, 2-100 V/div, 20ms), and rectifier current (3-10 A/div, 20ms) under step change of dc-bus voltage level.

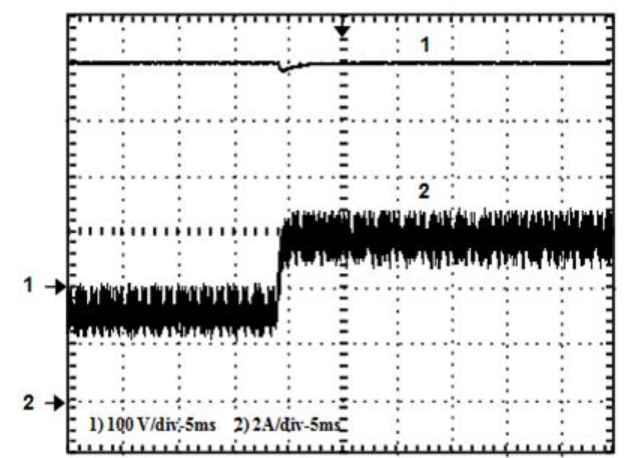

Fig. 20. Loading change effect. (a) DC-bus output voltage (1-100 V/div, 5ms), (b) load current (2-2 A/div, $5 \mathrm{~ms})$.

( $\mathrm{THD}=0.37 \%)$ and rectifier current $(\mathrm{THD}=17.03 \%)$, where the second-, fourth-, and fifth-order components are the most relevant. UPF operation was investigated $(\mathrm{PF}=0.991)$; since the rectifier current and the phase voltage are in phase. In conventional uncontrolled diode rectifiers, typical power factor and THD are about 0.94 and 35\%, respectively [27]. This improvement in the power factor represents more economic utilization of grid power.

\section{DC Reference Change Test}

Fig. 19 shows the reference voltage, $V_{d c}^{r}$ and the actual voltage, $V_{d c}$ under dc-bus voltage reference change. The main objective of this test is to investigate the control system performance under dc-bus voltage level change to large values for medium-voltage distribution applications. The dc-bus is connected to a 3-hp dc-motor operated at full load. A reference step change is applied and set to be increased from $400 \mathrm{~V}$ to $500 \mathrm{~V}$. The corresponding rectifier current at rated power (2.5 $\mathrm{kW}$ ) is also shown in Fig. 19. According to gain parameters design, it is noticed that the control operation has over damped transient response and there is no overshoot. Therefore, the overall dynamic performance has been greatly improved.

\section{Loading Effect}

The system performance is also investigated under load variation test. Fig. 20 shows the test results of the power converter under step change in the load current (from half to full load). We can notice that the load current is increased from 3 to $6 \mathrm{~A}$. On the other hand, dc-bus voltage still tracking its reference value with a small transient dipping of $4 \mathrm{~V}(1 \%)$.

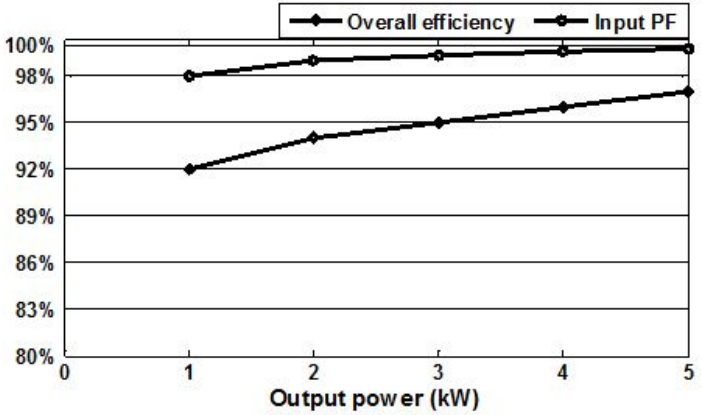

Fig. 21. Efficiency and input PF versus output power.

Fig. 21 shows the measured efficiencies. This demonstrates the expected improvement when compared with similar works.

\section{E. Application Considerations}

Practically, during initial voltage controller adjustment with the dc-bus capacitor uncharged, the initial dc-level will be very high, if it is above the capacitor voltage rating, it can destroy it. Avoiding that can be done by initially charging the dcbus capacitor to $60 \%$ of the reference dc-voltage. The freewheeling diodes of the IGBT module is working as a diode bridge rectifier during an initial charging. Once the capacitor is charged, the converter switching control signals should be connected, allowing the total power to flow through the IGBT switches.

\section{CONCLUSIONS}

In this paper, a new battery charging high frequency power converter module was developed for PHEV systems. The proposed three-phase semi-controlled rectification topology reduces the switching and conduction losses when compared to fully-controlled topology. A UPF operation (0.981) was achieved for better economic utilization of the grid absorbed power. The high efficiency operation was verified due to reduced number of switches (average 95\%). A second order SPLL was accurately designed for accurately detecting the phase angle during presence of the 5th and 7th harmonics. A fast control dynamic response was achieved ( 0.1 second) under different possible conditions; dc-reference step change and load variation. All the obtained results confirm the effectiveness of the proposed system for PHEV application.

\section{ACKNOWLEDGMENT}

This work was supported by Florida International University (FIU), Dissertation Year Fellowship (DYF). Part of this work is supported by grants from the Office of Naval Research and the US Department of Energy.

\section{REFERENCES}

[1] H. Oba, "Characteristics and analysis of efficiency of various hybrid systems," Report of Toyota Motor Corporation, pp. 935-957, 2004.

[2] M. Duvall, E. Knipping, "Environmental assessment of plug-in hybrid electric vehicles," EPRI, Vol. 2, Jul. 2007.

[3] A. W. Stienecker, M. A. Flute, and T. A. Stuart, "Improved battery charging in an ultracapacitor - Lead acid battery hybrid energy storage system for mild hybrid electric vehicles," SAE Paper, No. 2006-01-1123, 2006. 
[4] B. Spier and G. Gutmann, " $42-\mathrm{V}$ battery requirements lead-acid at its limits," Journal of Power Sources, Vol. 116, No. 1-2, pp. 99-104, Jul. 2003.

[5] M. Anderman, "The challenge to fulfill electrical power requirements of advanced vehicles," Journal of Power Sources, Vol. 127, No. 1-2, pp. 2-7, 2004.

[6] C. Kim, H. Park, C. Kim, G. Moon, and J. Lee, "Individual charge equalization converter with parallel primary winding of transformer for series connected lithium-ion battery strings in an HEV," Journal of Power Electronics, Vol. 9, No. 3, pp.472-480, May 2009.

[7] B. Lee, D. Shin, H. Song, H. Heo, and H. Kim, "Development of an advanced hybrid energy storage system for hybrid electric vehicles," Journal of Power Electronics, Vol. 9, No. 1, pp. 51-60, Jan. 2009.

[8] M. Amin and O. A. Mohammed, "Development of a grid-connected wind generation system utilizing high frequency-based three-phase semicontrolled rectifier-current source inverter," 26th IEEE APEC annual conference2011, pp. 645-652, 6-11 Mar. 2011.

[9] E. R. Motto, J. F. Donlon, and Y. Nagashima, "Optimizing 1200v IGBT modules for high frequency applications," APEC 2007, pp. 1254-1257, Mar. 2007.

[10] R. Noroozian, G. Gharehpetian, M. Abedi, and M. Mahmoodi, "Gridtied and stand-alone operation of distributed generation modules aggregated by cascaded boost converters," Journal of Power Electronics, Vol. 10, No. 1, pp. 97-105, Jan. 2010.

[11] J. Napoles, J. Leon, R. Portillo, L. Franquelo, and M. Aguirre, "Selective harmonic mitigation technique for high-power converters," IEEE Trans. Ind. Electron., Vol. 57, No. 7, pp. 2315-2323, Jul. 2010.

[12] P. Cheasty, J. Flannery, M. Meinhardt, A. Alderman, and S. Mathuna, "Benchmark of power packaging for $\mathrm{dc} / \mathrm{dc}$ and ac/dc converters," IEEE Trans. Power Electron., Vol. 17, No. 1, pp. 141-150, Jan. 2002.

[13] M. Malinowski, K. Gopakumar, J. Rodriguez, and M. Pérez, "A survey on cascaded multilevel inverters," IEEE Trans. Ind. Electron., Vol. 57, No. 7, pp.2197-2206, Jul. 2010.

[14] H. Fujita, "A resonant gate-drive circuit capable of high-frequency and high-efficiency operation," IEEE Trans. Power Electron., Vol. 25, No. 4, pp. 962-969, Apr. 2010.

[15] N. King, E. Narayanan, L. Coulbeck, A. Crane, and R. Dudley, "Comparison of trench gate IGBT and CIGBT devices for increasing the power density from high power modules," IEEE Trans. Power Electron., Vol. 25, No. 3, pp. 583-591, Mar. 2010.

[16] H. Ohashi, "High power density design methodology," IEEJ, Vol. 102, No. 3, pp. 168-171, 2002 (in Japanese).

[17] I. Omura, W. Saito, T. Domon, and K. Tsuda, "Gallium nitride power HEMT for high switching frequency power electronics," IWPSD, pp. 781-786, Dec. 2007.

[18] C. Kim, S. Han, K. Park, and G. Moon, "A new high efficiency ZVZCS bidirectional dc/dc converter for HEV $42 \mathrm{~V}$ power systems," Journal of Power Electronics, Vol. 6, No. 3, pp. 271-278, Jul. 2006.

[19] A. Pandey, B Singh, and D. Kothari, "Comparative evaluation of single phase unity power factor ac-dc boost converter topologies," IE (I)-EL Vol. 85, pp. 102-109, Sep. 2004.

[20] M. H. Rashid, Power Electronics Handbook, San Diego, CA: Academic Press, 2001

[21] J. Rodríguez, J. Dixon, J. Espinoza, J. Pontt, and P. Lezana, "PWM regenerative rectifiers: state of the art," IEEE Trans. Ind. Electron., Vol. 52, No. 1, pp. 5 -22, Feb. 2005.

[22] IEEE Recommended Practices and Requirements for Harmonic Control in Electrical Power Systems, IEEE Standard 519, 1992, 2010.

[23] N. Mohan, T. Undeland, and W. Robbins, Power Electronics: Converters, Applications, and Design, New York: John Wiley \& Sons, 2003.

[24] P. Krein, J. Bentsman, R. Bass, and B. Lesieutre, "On the use of averaging for the analysis of power electronic systems," IEEE Trans. Power Electron., Vol. 5, No. 2, pp. 182-190, Apr. 1990.

[25] A. Tilli and A. Tonielli, "Sequential design of hysteresis current controller for three-phase inverter," IEEE Trans. Ind. Electron., Vol. 45, No. 5, pp. 771-781, Oct. 1998.

[26] M. M. N. Amin and O. A. Mohammed, "Vector oriented control of voltage source PWM inverter as a dynamic var compensator for wind energy conversion system connected to utility grid," in APEC' 2010 Conf., Vol. I, pp. 1640-1650, Feb. 2010.

[27] H. Suryawanshi, M. Ramteke, K. Thakre, and V. Borghate, "Unitypower-factor operation of three-phase ac-dc soft switched converter based on boost active clamp topology in modular approach," IEEE Trans. Power Electron., Vol. 23, No. 1, pp. 229-236, Jan. 2008.

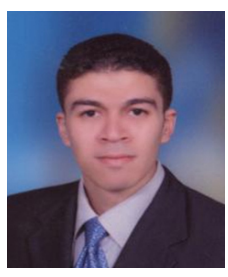

Mahmoud M. Amin (S'09) received the B.Sc. degree in Electrical Power \& Machines engineering, and the M.S. degree in Electrical Engineering, all from Faculty of Engineering, Helwan University, Egypt, in 2003 and 2008, respectively. He is currently a Ph.D. Candidate (Research Assistant) in the energy systems research laboratory, Electrical and Computer Engineering Department at Florida International University. His research interests include power electronic applications in sustainable energy conversion systems and smart grid. He is the recipient of the Graduate Student Association (GSA) scholarly forum prize paper award 2010 as well as the IEEE PES GM 2010 graduate student poster contest award. Also, He is the recipient of the Dissertation Year Fellowship (DYF) in 2011. $\mathrm{He}$ is the author of more than 20 scientific papers presented at international conferences or published in reviewed journals.

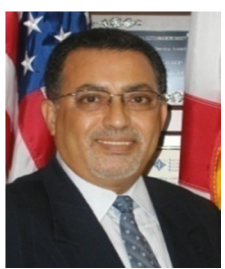

Osama A. Mohammed (S'79, M'83, SM'84, F'94): Professor Mohammed received his M.S. and Ph.D degrees in Electrical Engineering from Virginia Polytechnic Institute and State University. He has many years of teaching, curriculum development, research and industrial consulting experience. He authored and co-authored more than 300 technical papers in the archival literature as well as in National and International Conference records in addition to additional numerous technical and project reports and monographs. He is author of book chapters including; Chapter 8 on direct current machines in the Standard Handbook for Electrical Engineers, 15th Edition, McGraw-Hill, 2007 and a book Chapter entitled "Optimal Design of Magnetostatic Devices: the genetic Algorithm Approach and System Optimization Strategies," in the Book entitled: Electromagnetic Optimization by Genetic Algorithms, John Wiley \& Sons, 1999. Professor Mohammed specializes in Electrical Energy Systems especially in areas related to alternate and renewable energy systems. He is also interested in design optimization of electromagnetic devices, Artificial Intelligence Applications to Energy Systems as well as Electromagnetic Field Computations in Nonlinear Systems for these energy applications. He has current interest in Shipboard power systems and integrated motor drives. He is also interested in the application communication and sensor networks for the distributed control of power grids. Dr. Mohammed has been successful in obtaining a number of research contracts and grants from industries and Federal government agencies. He has a current active and funded research programs in several areas funded by the office of Naval Research and the US Department of Energy. Professor Mohammed is also interested in developing learning environments and educational techniques for Internet based delivery systems and virtual laboratories. Professor Mohammed is a Fellow of IEEE and is a recipient of the 2010 IEEE PES Cyril Veinott Electromechanical Energy Conversion Award. Professor Mohammed is also a Fellow of the Applied Computational Electromagnetic Society. He is Editor of IEEE Transactions on Energy Conversion, IEEE Transactions on Magnetics-Conferences, as well as an Editor of COMPEL He also received many awards for excellence in research, teaching and service to the profession and has chaired sessions and programs in numerous International Conferences in addition to delivering numerous invited lectures at scientific organizations in around the world. Professor Mohammed serves as the International Steering Committee Chair for the IEEE International Electric Machines and Drives Conference (IEMDC) and the IEEE Biannual Conference on Electromagnetic Field Computation (CEFC). Professor Mohammed was the General Chair of the 2009 IEEE IEMDC conference held in CityMiami Florida, May 3-6 2009 and was the Editorial Board Chairman for the IEEE CEFC2010 held in Chicago, IL USA, May 9-12, 2010. Professor Mohammed was also the general chair of the IEEE CEFC 2006 held in Miami, Florida, April 30 - May 3, 2006. He was also general chair of the 19th annual Conference of the Applied Computational Electromagnetic Society ACES-2006 held in Miami, Florida March 14-17, 2006. He was the General Chairman of the 1993 COMPUMAG International Conference and was also the General Chairman of the 1996 IEEE International Conference on Intelligent Systems Applications to Power Systems (ISAP'96) Dr. Mohammed has chaired the Electric Machinery Committee for IEEE PES was the Vice Chair and Technical Committee Program Chair for the IEEE PES Electric Machinery Committee for a number of years. He was a member of the IEEE/Power Engineering Society Governing Board (1992-1996) and was the Chairman of the IEEE Power Engineering Society Constitution and Bylaws committee. He also serves as chairman, officer or as an active member on several IEEE PES committees, sub-committees and technical working groups. 